\title{
Cardiometabolic Risk in Overweight and Obese Children in Bangladesh
}

\author{
Muhammad Abdul Hannan', Tahniyah Haq ${ }^{2 *}$, Muhammad Abu Hasanat ${ }^{2}$, \\ Muhammad Fariduddin² \\ ${ }^{1}$ Sherpur District Hospital, Sherpur, Bangladesh \\ ${ }^{2}$ Department of Endocrinology, Bangabandhu Sheikh Mujib Medical University (BSMMU), Dhaka, Bangladesh \\ Email: mahannans97@gmail.com, ^tahniyah81@bsmmu.edu.bd, hasanatdr@yahoo.com,dr.md.fariduddin@gmail.com
}

How to cite this paper: Hannan, M.A., Haq, T., Hasanat, M.A. and Fariduddin, M. (2019) Cardiometabolic Risk in Overweight and Obese Children in Bangladesh. Open Journal of Endocrine and Metabolic Diseases, 9, 103-117.

https://doi.org/10.4236/ojemd.2019.910011

Received: September 24, 2019

Accepted: October 26, 2019

Published: October 29, 2019

Copyright $\odot 2019$ by author(s) and Scientific Research Publishing Inc. This work is licensed under the Creative Commons Attribution International License (CC BY 4.0).

http://creativecommons.org/licenses/by/4.0/

\begin{abstract}
Introduction: Childhood obesity is increasing dramatically and represents an important public health issue due to associated metabolic and cardiovascular co-morbidities. Very limited data are available regarding cardiometabolic risk factors among this group in Bangladesh. Objective: To observe the cardiometabolic risk factors in overweight and obese children. Methods: This cross-sectional study was carried out in 88 overweight and obese children recruited consecutively by using CDC percentile chart for body mass index (BMI) in children between January 2017 and March 2018 in the Department of Endocrinology, Bangabandhu Sheikh Mujib Medical University, Dhaka, Bangladesh. After completing a questionnaire and relevant clinical examination, blood was collected for fasting plasma glucose (FPG), insulin, HbA1c, lipid profile and C-reactive protein (CRP). Homeostasis Model Assessment of Insulin Resistance (HOMA-IR) was used to determine insulin resistance. Results: Central obesity (100\%), dyslipidaemia (88.6\%), raised CRP (81.8\%) and metabolic syndrome (69.3\%) were the most common cardiometabolic risk factors. Children with grade 3 obesity had significantly higher systolic blood pressure $(115.57 \pm 11.60$ vs $105.71 \pm 8.84 \mathrm{mmHg}, \mathrm{p}=0.043)$ and insulin resistance $(7.15 \pm 4.97$ vs $3.53 \pm 2.04, \mathrm{p}=0.017)$ than grade 1 obesity. Blood pressure, insulin resistance and CRP increased while high density lipoprotein (HDL) decreased with increasing severity of obesity. BMI z score was a significant predictor of systolic blood pressure; waist circumference was an independent predictor of diastolic blood pressure and HDL; waist height ratio best predicted insulin resistance, CRP and total cholesterol in overweight/obese children. Conclusions: We have observed a high frequency of cardiometabolic risk factors in overweight and obese children and they increased worsened with increasing grade of obesity.
\end{abstract}




\section{Keywords}

Cardiometabolic Risk, Overweight, Obese

\section{Introduction}

Worldwide prevalence of childhood obesity has increased greatly over the past two to three decades. Childhood obesity has more than quadrupled in adolescents aged 12 - 19, increasing from $5 \%$ in 1980 to nearly $21 \%$ in 2012 [1]. It represents one of the most important public health issues due to its associated metabolic and cardiovascular comorbidities [2]. Obesity in children predisposes them to cardiometabolic disorders such as hypertension, dyslipidaemia and insulin resistance [3]. A number of studies have demonstrated that risk factors for cardiovascular disease such as high blood pressure, dyslipidaemia, diabetes and overweight/obesity cluster together in children and are significantly inter-correlated [4]. Obesity represents the major risk factor for the development of insulin resistance [5] and metabolic syndrome [6] in children and adolescents. Obese children and adolescents have a more unfavourable lipid profile than children and adolescents with normal body weight [7] [8]. In obese children, increased level of inflammatory marker such as C-reactive protein (CRP) has been shown to progressively increase with insulin resistance [9]. As overweight and obesity is likely to follow through into adulthood, there is a greater risk of developing cardiovascular disease in the long term [10] [11]. Therefore, it is important to recognize and address this issue early during childhood. The aim of this study was to look into cardiometabolic risk factors in overweight and obese children.

\section{Material and Methods}

This cross-sectional study was carried out at Bangabandhu Sheikh Mujib Medical University (BSMMU) from January 2017 to March 2018.

\subsection{Ethics}

The study was approved by Institutional Research Board, BSMMU (No. BSMMU/2017/24). Written informed assent was taken from each participant.

\subsection{Study Design}

Overweight and obese 6 - 18 year old children attending in and outpatient department of Endocrinology were recruited by non-purposive consecutive sampling. Overweight and obesity was determined by calculating body mass index (BMI) which was plotted on Centers for Disease Control (CDC) chart. Those with syndromic obesity, endocrinopathies such as hypothyroidism, Cushing syndrome, hypothalamic tumour, insulinoma, medications causing weight gain (corticosteroids, pizotifen, sodium valproate, $\beta$-blockers, anti diabetic drugs, an- 
tipsychotics), chronic infection or inflammation, diabetes and diseases or medications that alter blood pressure or lipid metabolism were excluded. Cardiometabolic risk factors (central obesity, hypertension, raised CRP, insulin resistance, impaired fasting glucose or diabetes mellitus, dyslipidemia) and presence of metabolic syndrome were determined from clinical examination and laboratory investigation.

The CDC age- and sex-specific growth chart was used to classify participants as overweight and obese. Overweight was defined as BMI at or greater than 85th to less than 95th percentile and obesity as BMI at or greater than 95th percentile for age and sex [12]. Obesity was further divided into 3 grades: Grade I obesity BMI at or above 95th percentile to less than $120 \%$ of the 95th percentile, Grade II obesity - BMI at or above $120 \%$ to less than $140 \%$ of the 95 th percentile, or BMI at or above $35 \mathrm{~kg} / \mathrm{m}^{2}$ and Grade III obesity - BMI at or above $140 \%$ of the 95th percentile, or BMI at or above $40 \mathrm{~kg} / \mathrm{m}^{2}$ [13]. Because the body-mass index varies according to age, we standardized the value for age and sex with the use of conversion to a $\mathrm{z}$ score from the website [14]. Central obesity was defined as waist circumference $(\mathrm{WC}) \geq 90$ percentile and/or waist height ratio (WHtR) $\geq$ 0.5 [15]. Hypertension was taken as systolic and/or a diastolic blood pressure $\geq$ 95th percentile for age, gender, and height according to the "Fourth Report on Diagnosis, Evaluation, and Treatment of High Blood Pressure in Children and Adolescents" [16] [17]. The cut point of raised CRP for increased cardiovascular risk was taken at $2 \mathrm{mg} / \mathrm{l}$ [18] [19]. Homeostasis model assessment of insulin resistance (HOMA-IR) value above 3 (corresponds to the 95th percentile healthy reference children) was regarded as presence of insulin resistance [20]. Impaired fasting glucose (IFG) was defined as fasting plasma glucose (FPG) levels between 5.6 and $6.9 \mathrm{mmol} / \mathrm{l}$ and diabetes when FPG $\geq 7 \mathrm{mmol} / \mathrm{l}$ [21]. Dyslipidemia was defined as at least one abnormal value for High Density Lipoprotein (HDL), Low Density Lipoprotein (LDL), total cholesterol (TC) or triglyceride (TG) [22]. Table 1 below shows abnormal cutoffs of individual blood lipids in children.

The definition for metabolic syndrome in children was taken from National Cholesterol Education program (NCEP) [15] in which children must have at least three of the given criteria: 1) Serum Triglyceride $\geq 110 \mathrm{mg} / \mathrm{dL}$, 2) Serum HDL-C $\leq 40 \mathrm{mg} / \mathrm{dL}$, 3) Fasting plasma glucose $\geq 100 \mathrm{mg} / \mathrm{dL}$, 4) Waist circumference $\geq 90$ th percentile for age and gender and 5) systolic or diastolic blood pressure $\geq 90$ th percentile for age and sex [15].

Weight was measured using an electronic digital weighing machine to the nearest $0.1 \mathrm{~kg}$, with the participant wearing light clothes and without shoes. Height was measured by a portable wall-mounted stadiometer to the nearest 0.1 $\mathrm{cm}$ with the participant without shoes in the erect position, back against the wall with his/her head held in Frankfurt horizontal plane with a right-angled triangle resting on the scalp and against the wall. WC was measured midway between the lowest rib and the superior border of the iliac crest by using a non-extensible and non-elastic measuring tape in mid respiration and inferences were drawn in percentiles WHtR was calculated by the formula WC in centimeters divided by 
Table 1. Plasma lipid ranges for children and adolescents [22].

\begin{tabular}{cccc}
\hline Category & Acceptable $(\mathrm{mg} / \mathrm{dl})$ & Borderline $(\mathrm{mg} / \mathrm{dl})$ & High $(\mathrm{mg} / \mathrm{dl})$ \\
\hline TC & $<170$ & $170-199$ & $\geq 200$ \\
LDL-C & $<110$ & $110-129$ & $\geq 130$ \\
HDL-C & $>45$ & $45-40$ & $<40$ \\
TG & & & \\
$0-9$ (years) & $<75$ & $75-99$ & $\geq 100$ \\
$10-19$ (years) & $<90$ & $90-129$ & $\geq 130$ \\
\hline
\end{tabular}

body height in centimeters [23]. Blood pressure was measured according to method described by the Seventh Report of the Joint National Committee [24]. It was measured three times by the same individual with aneroid sphygmomanometer (Yamasu) after calibration and standardization and mean value was recorded. Ten $\mathrm{ml}$ of venous blood was collected after a 12 hour fast for fasting glucose, HbA1C, lipid profile and CRP. Glucose was measured by hexokinase/G-6-PDH method. Quantitative determination of serum insulin levels was done by chemiluminescent immunoassay method using Access Immunoassay System (REF- 33410) and HbA1c was measured using the NGSP certified method (Bio-Rad D-10 ${ }^{\mathrm{TM}}$ Hemoglobin $\mathrm{A}_{1} \mathrm{c}$ Program 220-0101, USA). Cardiophase CRP reagent was used for the quantitative determination of CRP in human serum by means of particle enhanced immune nephelometry (BN 2 and BN prospec system). TC, TG, and HDL-C were measured by automated analyzer (Architect Plus ci8200). LDL-C was calculated with the use of the Friedewald formula: LDL-C = TC - HDL-C - (TG/5). The HOMA-IR index (a measure of insulin resistance) was calculated as the product of the fasting plasma insulin level $(\mathrm{mU} / \mathrm{L})$ and the fasting plasma glucose level (mM/L), divided by 22.5 [25].

\subsection{Sample Size Estimation}

Sample size $(n)$ was determined by the formula used in cross sectional studies ( $n$ $=Z^{2} p q / d^{2}$ ) with $95 \%$ confidence interval (value of standard normal distribution $(Z)=1.96)$ and $10 \%$ margin of error $(d)$. The prevalence $(p)$ of metabolic syndrome in childhood obesity was taken to be 0.307 [26]. Taking $10 \%$ drop out, sample size was calculated to be 88 .

\subsection{Statistical Analysis}

All values were expressed as means $\pm \mathrm{SD}$ or frequencies. Distributions of continuous variables were examined for skewness and variables that were not normally distributed (CRP, HOMA-IR, total cholesterol and triglyceride) were log-transformed for analysis. However, for clarity of interpretation, results were expressed as untransformed values. One way ANOVA was used to compare the means of cardiometabolic risks among overweight and different grades of obesity with post hoc analysis where appropriate. Fisher's Exact test was used to see 
the frequency of metabolic syndrome in different grades of obesity. The correlation between two variables was studied with the Pearson's correlation coefficient test. Multiple linear regression (backward method) was used to evaluate the association between cardiometabolic risk factors and different measures of obesity. Blood pressure, HOMA-IR and CRP were entered as dependent variables. The SPSS version 23.0 was used for the statistical analyses.

\section{Results}

In this study, 88 overweight and obese children with a mean age of $11.48 \pm 2.72$ years were enrolled. The male to female ratio was 1.4:1. Their mean BMI was $29.31 \pm 5.11 \mathrm{~kg} / \mathrm{m}^{2}$, with a range from 21.1 to $46.9 \mathrm{~kg} / \mathrm{m}^{2}$. The mean BMI z score was $2.19 \pm 0.36$. Table 2 shows the frequency of overweight and different degree of obesity, where maximum number of children had grade 1 followed by grade 2 obesity.

\subsection{Cardiometabolic Risks}

The cardiometabolic risk factors of the study population are depicted in Table 3 and Table 4. The mean WC, WHtR, HOMR-IR, CRP, TG were higher than normal. $100 \%$ of the participants had central obesity. Among the children with hypertension, systolic and diastolic hypertension was present in $12.5 \%$ and $31.8 \%$ cases respectively. Dyslipidaemia was present in the majority of the children, with low HDL in $68.2 \%$ and hypertriglyceridemia in $63.6 \%$. Although $60 \%$ of the participants had raised HOMA-IR, only $8 \%$ had impaired glucose tolerance. Among 88 over weight and obese children metabolic syndrome was present in more than $50 \%$ cases. Among the children with metabolic syndrome, $36.4 \%$ cases had 3 components, $28.4 \%$ had 4 and $4.5 \%$ children had all the 5 components. All of the children with metabolic syndrome had central obesity whereas hypertriglyceremia, low HDL-C and hypertension were present in $72.7 \%, 69.3 \%$ and $48.9 \%$ participants respectively.

\subsection{Cardiometabolic Risk and Obesity}

There was significant difference in WC and WHtR among overweight and different grades of obesity. There was significantly higher SBP (115.57 \pm 11.60 vs $105.71 \pm 8.84 \mathrm{mmHg}, P 0.043)$ and insulin resistance $(7.15 \pm 4.97$ vs $3.53 \pm 2.04$, $P$ 0.017) in children with grade 3 compared to grade 1 obesity. Trend of values increased but was not statistically significant in case of diastolic blood pressure and FPG (Table 5). There was also a significant association between systolic hypertension and severity of obesity $(P 0.015)$ (Table 6$)$.

All of the overweight children had metabolic syndrome. Maximum percentage of metabolic syndrome was found in grade 3 obesity $(80 \%)$ and lowest in grade 1 $(62.9 \%)$. Fisher's Exact test did not show any significant difference in the frequency of metabolic syndrome among different grades of obesity $(P 0.188)$ (Table 5). 
Table 2. Frequency of overweight and different grades of obesity $(n=88)$.

\begin{tabular}{cc}
\hline Grade of obesity & $\begin{array}{c}\text { Frequency } \\
\mathrm{n}(\%)\end{array}$ \\
\hline Overweight & $7(8)$ \\
Grade 1 obesity & $35(39.8)$ \\
Grade 2 obesity & $31(35.2)$ \\
Grade 3 obesity & $15(17)$ \\
\hline
\end{tabular}

Within parentheses are percentages over column total.

Table 3. Cardiometabolic risk factors of the study population $(\mathrm{n}=88)$.

\begin{tabular}{cccc}
\hline Variables & Normal value & Mean \pm SD & Minimum, maximum \\
\hline WC $(\mathrm{cm})$ & $<90$ percentile & $92.65 \pm 11.73$ & 70,134 \\
WHtR & $<0.5$ & $0.62 \pm 0.06$ & $0.5,0.8$ \\
SBP $(\mathrm{mmHg})$ & $<95^{\text {th }}$ centile & $109.92 \pm 12.29$ & 80,158 \\
DBP $(\mathrm{mmHg})$ & $<95^{\text {th }}$ centile & $75.39 \pm 9.09$ & 60,105 \\
FPG $(\mathrm{mmol} / \mathrm{l})$ & $<5.6$ & $4.75 \pm 0.8$ & $3.4,8.2$ \\
Fasting insulin $(\mu \mathrm{iu} / \mathrm{ml})$ & $<22$ & $20.27 \pm 13.0$ & $1.5,70.5$ \\
HOMA-IR & $<3$ & $4.51 \pm 3.63$ & $0.25,20.22$ \\
HbAlc $(\%)$ & $<5.7$ & $5.6 \pm 0.7$ & $4.5,9.1$ \\
TC $(\mathrm{mg} / \mathrm{dl})$ & $<170$ & $178.53 \pm 40.8$ & 96,354 \\
LDL-C $(\mathrm{mg} / \mathrm{dl})$ & $<110$ & $110.08 \pm 36.57$ & 36,279 \\
HDL-C $(\mathrm{mg} / \mathrm{dl})$ & $<45$ & $37.48 \pm 7.8$ & 13,57 \\
TG $(\mathrm{mg} / \mathrm{dl})$ & $<75(0-9$ yrs $) / 90(10-19 \mathrm{yrs})$ & $163.35 \pm 97.93$ & 44,862 \\
CRP $(\mathrm{mg} / \mathrm{dl})$ & $<2$ & $7.48 \pm 7.44$ & $0.17,46.70$ \\
\hline
\end{tabular}

Normal values are in relation to age and sex of the child [8]-[15]. WC $=$ Waist Circumference, WHtR = Waist height ratio, $\mathrm{SBP}=$ Systolic blood pressure, $\mathrm{DBP}=$ Diastolic blood pressure, $\mathrm{FPG}=$ Fasting plasma glucose, HbAlc $=$ Glycosylated hemoglobin \%, HOMA-IR $=$ Homeostasis model assessment of insulin resistance, $\mathrm{TC}=$ Total cholesterol, LDL-C $=$ Low density lipoprotein-cholesterol, $\mathrm{TG}=$ Triglyceride, HDL-C $=$ High-density lipoprotein-cholesterol, $\mathrm{CRP}=\mathrm{C}$-reactive protein .

Table 4. Frequency of cardiometabolic risk factors of the study population $(n=88)$.

\begin{tabular}{cc}
\hline Risk factor & Frequency n (\%) \\
Male sex & $52(59.1)$ \\
Central obesity & $88(100)$ \\
Pre HTN/HTN & $43(48.9)$ \\
Dyslipidemia & $78(88.6)$ \\
Insulin resistance & $48(59.3)$ \\
Raised CRP & $72(81.8)$ \\
IFG/DM & $7(8)$ \\
Metabolic syndrome & $61(69.3)$ \\
\hline
\end{tabular}

HTN $=$ hypertension, $\mathrm{IFG}=$ impaired fasting glucose, $\mathrm{DM}=$ Diabetes mellitus, $\mathrm{CRP}=\mathrm{C}$-reactive protein. 
Table 5. Cardiometabolic risk factors among different grades of obesity $(n=88)$.

\begin{tabular}{cccccc}
\hline Variables & $\begin{array}{c}\text { Overweight } \\
\mathrm{n}=7\end{array}$ & $\begin{array}{c}\text { Grade } 1 \\
\mathrm{n}=35\end{array}$ & $\begin{array}{c}\text { Grade } 2 \\
\mathrm{n}=31\end{array}$ & $\begin{array}{c}\text { Grade } 3 \\
\mathrm{n}=15\end{array}$ & Pvalue \\
\hline & & \multicolumn{2}{c}{$($ Mean $\pm \mathrm{SD})$} & & \\
\hline Age (years) & $13.29 \pm 2.89$ & $11.83 \pm 2.61$ & $10.77 \pm 2.54$ & $11.27 \pm 3.25$ & 0.117 \\
WC (cm) & $87.00 \pm 8.35$ & $88.94 \pm 8.82$ & $92.84 \pm 11.31$ & $103.53 \pm 13.65$ & $<0.001$ \\
WHtR & $0.56 \pm 0.04$ & $0.60 \pm 0.04$ & $0.63 \pm 0.05$ & $0.69 \pm 0.06$ & $<0.001$ \\
SBP (mmHg) & $109.29 \pm 18.36$ & $105.71 \pm 8.84$ & $112.08 \pm 13.35$ & $115.57 \pm 11.60$ & 0.038 \\
DBP (mmHg) & $72.86 \pm 11.13$ & $72.77 \pm 7.50$ & $77.26 \pm 10.55$ & $78.82 \pm 6.68$ & 0.073 \\
FPG (mmol/l) & $4.71 \pm 0.86$ & $4.63 \pm 0.49$ & $4.81 \pm 0.93$ & $4.94 \pm 1.05$ & 0.609 \\
HbAlc (\%) & $5.69 \pm 0.56$ & $5.53 \pm 0.39$ & $5.74 \pm 0.98$ & $5.67 \pm 0.70$ & 0.664 \\
TC (mg/dl) & $171.71 \pm 25.77$ & $174.06 \pm 40.30$ & $187.35 \pm 45.28$ & $173.93 \pm 38.10$ & 0.538 \\
TG (mg/dl) & $151.86 \pm 27.89$ & $167.43 \pm 135.86$ & $158.81 \pm 69.87$ & $168.60 \pm 61.60$ & 0.908 \\
LDL-C (mg/dl) & $103.03 \pm 20.21$ & $108.90 \pm 36.40$ & $115.08 \pm 40.17$ & $105.80 \pm 36.83$ & 0.787 \\
HDL-C (mg/dl) & $38.14 \pm 7.82$ & $36.51 \pm 6.87$ & $39.48 \pm 9.50$ & $35.27 \pm 5.56$ & 0.286 \\
HOMA-IR & $3.96 \pm 3.71$ & $3.53 \pm 2.04$ & $4.42 \pm 3.76$ & $7.15 \pm 4.97$ & 0.017 \\
CRP (mg/dl) & $4.15 \pm 4.34$ & $7.41 \pm 8.32$ & $7.16 \pm 6.37$ & $9.86 \pm 8.30$ & 0.397 \\
\hline
\end{tabular}

Comparison done by one-way ANOVA. Tukey's post hoc analysis showed significant difference in WC between overweight vs Gr3, Gr1 vs Gr2 vs Gr3, in WHtR between overweight vs Gr2 vs Gr3, Gr1 vs Gr2 vs Gr3, in SBP between Gr1 vs Gr3. In HOMA-IR between Gr1 vs Gr3, WC = Waist Circumference, WHtR = Waist height ratio, $\mathrm{SBP}=$ Systolic blood pressure, $\mathrm{DBP}=$ Diastolic blood pressure, $\mathrm{FPG}=$ Fasting plasma glucose, HbAlc = Glycosylated hemoglobin \%, HOMA-IR = Homeostasis model assessment of insulin resistance, $\mathrm{TC}=$ Total cholesterol, $\mathrm{LDL}-\mathrm{C}=$ Low density lipoprotein-cholesterol, $\mathrm{TG}=$ Triglyceride, HDL-C $=$ High-density lipoprotein-cholesterol, $\mathrm{CRP}=\mathrm{C}$-reactive protein.

Table 6. Frequency of cardiometabolic risk factors among different grades of obesity $(\mathrm{n}=$ 88).

\begin{tabular}{cccccc}
\hline Variables & $\begin{array}{c}\text { Overweight } \\
\mathrm{n}=7\end{array}$ & $\begin{array}{c}\text { Grade 1 } \\
\text { obesity } \\
\mathrm{n}=35\end{array}$ & $\begin{array}{c}\text { Grade 2 } \\
\text { obesity } \\
\mathrm{n}=31\end{array}$ & $\begin{array}{c}\text { Grade 2 } \\
\text { obesity } \\
\mathrm{n}=15\end{array}$ & $P$ value \\
\hline Systolic pre HTN/HTN n (\%) & $02(28.6)$ & $02(5.7)$ & $08(25.8)$ & $06(40)$ & 0.015 \\
Diastolic pre HTN/HTN n (\%) & $03(42.9)$ & $11(31.4)$ & $17(54.8)$ & $10(66.7)$ & 0.084 \\
Pre HTN/HTN n (\%) & $03(42.9)$ & $12(34.3)$ & $17(54.8)$ & $11(73.3)$ & 0.068 \\
IFG/DM n (\%) & $01(14.3)$ & $01(2.9)$ & $04(12.9)$ & $01(6.7)$ & 0.441 \\
Insulin resistance n (\%) & $03(42.9)$ & $16(51.6)$ & $17(58.6)$ & $12(85.7)$ & 0.127 \\
Dyslipidemia n (\%) & $07(100)$ & $31(88.6)$ & $26(83.9)$ & $14(93.3)$ & 0.750 \\
Raised CRP n (\%) & $05(71.4)$ & $27(77.1)$ & $25(80.6)$ & $15(100)$ & 0.148 \\
Metabolic syndrome (\%) & $7(100)$ & $22(62.9)$ & $20(64.5)$ & $12(80)$ & 0.188 \\
\hline
\end{tabular}

Within parenthesis percentages over column total. $P$ value obtained by Chi square test. HTN $=$ hypertension, $\mathrm{IFG}=$ impaired fasting glucose, $\mathrm{DM}=$ Diabetes mellitus, $\mathrm{CRP}=\mathrm{C}$-reactive protein.

There was significant positive correlation between SBP $(r=0.224, P 0.036)$, DBP $(\mathrm{r}=0.231, P 0.030)$, HOMA-IR $(\mathrm{r}=0.322, P 0.003)$ and CRP $(\mathrm{r}=0.317, P$ 
0.003) with BMI z score (Table 6). WC significantly increased with increasing SBP ( $\mathrm{r}=0.426, P<0.001)$, DBP ( $\mathrm{r}=0.438, P<0.001)$, HOMA-IR ( $\mathrm{r}=0.435, P<$ $0.001)$ and decreasing HDL-C $(\mathrm{r}=-0.212, P$ 0.047). WHtR significantly increased with increasing SBP $(\mathrm{r}=0.256, P 0.016), \mathrm{DBP}(\mathrm{r}=0.244, P$ 0.022), HOMA-IR ( $\mathrm{r}=0.44, P<0.001)$ and CRP $(\mathrm{r}=0.356, P 0.001)$ (Table 7$)$.

The association between cardiometabolic risk factors and different measures of obesity were assessed using a multiple linear regression model, where covariates which were not statistically significant were removed from the model (Table 8). BMI z score was linearly related to systolic blood pressure. When BMI $\mathrm{z}$ score increased by one unit, systolic blood pressure increased by 0.446 units ( $\beta$ $=0.446, P$ 0.001). Waist circumference was linearly related to diastolic blood pressure and HDL. When waist circumference increased by one unit, diastolic blood pressure increased by 0.339 units $(\beta=0.339, P<0.001)$ and HDL decreased by 0.141 units $(\beta=-0.141, P 0.047)$. Waist height ratio was linearly related to insulin resistance, CRP and total cholesterol. When waist height ratio increased by one unit, HOMA-IR increased by 2.516 units $(\beta=2.516, P<0.001)$, CRP increased by 2.677 units $(\beta=2.677, P 0.001)$, total cholesterol increased by 0.717 units $(\beta=0.717, P 0.006)$.

\section{Discussions}

Childhood overweight and obesity have a strong association with different cardiometabolic risk factors. The frequency of risk factors and their association with severity of obesity were explored in this study. Majority of children in this study had grade 1 followed by grade 2 obesity. Central obesity, dyslipidaemia, raised CRP and metabolic syndrome were the most common cardiometabolic

Table 7. Correlation of obesity with cardiometabolic risk factors $(\mathrm{n}=88)$.

\begin{tabular}{cccccccc}
\hline Variables & \multicolumn{2}{c}{ BMI z score } & \multicolumn{2}{c}{ WC } & \multicolumn{2}{c}{ WHtR } \\
\hline r & Pvalue & r & $P$ value & r & $P$ value \\
\hline SBP $(\mathrm{mmHg})$ & $\mathbf{0 . 2 2 4}$ & $\mathbf{0 . 0 3 6}$ & $\mathbf{0 . 4 2 6}$ & $<\mathbf{0 . 0 0 1}$ & $\mathbf{0 . 2 5 6}$ & $\mathbf{0 . 0 1 6}$ \\
DBP $(\mathrm{mmHg})$ & $\mathbf{0 . 2 3 1}$ & $\mathbf{0 . 0 3 0}$ & $\mathbf{0 . 4 3 8}$ & $<\mathbf{0 . 0 0 1}$ & $\mathbf{0 . 2 4 4}$ & $\mathbf{0 . 0 2 2}$ \\
FPG $(\mathrm{mmol} / \mathrm{l})$ & 0.109 & 0.312 & 0.209 & 0.051 & 0.175 & 0.102 \\
TC $(\mathrm{mg} / \mathrm{dl})$ & 0.06 & 0.577 & -0.116 & 0.283 & 0.114 & 0.290 \\
TG $(\mathrm{mg} / \mathrm{dl})$ & 0.025 & 0.818 & 0.041 & 0.703 & 0.122 & 0.259 \\
LDL-C (mg/dl) & 0.042 & 0.700 & -0.021 & 0.847 & 0.144 & 0.180 \\
HDL-C (mg/dl) & 0.004 & 0.971 & -0.212 & $\mathbf{0 . 0 4 7}$ & -0.059 & 0.584 \\
HOMA-IR & $\mathbf{0 . 3 2 2}$ & $\mathbf{0 . 0 0 3}$ & $\mathbf{0 . 4 3 5}$ & $<\mathbf{0 . 0 0 1}$ & $\mathbf{0 . 4 4 0}$ & $<\mathbf{0 . 0 0 1}$ \\
CRP (mg/dl) & $\mathbf{0 . 3 1 7}$ & $\mathbf{0 . 0 0 3}$ & 0.193 & 0.071 & $\mathbf{0 . 3 5 6}$ & $\mathbf{0 . 0 0 1}$ \\
\hline
\end{tabular}

$\mathrm{r}=$ Pearson's correlation coefficient, $P<0.05$ was taken as significant. $\mathrm{SBP}=$ Systolic blood pressure, $\mathrm{DBP}=$ Diastolic blood pressure, FPG = Fasting plasma glucose, HOMA-IR = Homeostasis model assessment of insulin resistance, $\mathrm{TC}=$ Total cholesterol, $\mathrm{LDL}-\mathrm{C}=\mathrm{Low}$ density lipoprotein-cholesterol, $\mathrm{TG}=$ Triglyceride, HDL-C = High-density lipoprotein-cholesterol, CRP = C-reactive protein. 
Table 8. Results of multiple regression analysis: changes in cardiometabolic risk factors associated with different measures of obesity $(n=88)$.

\begin{tabular}{|c|c|c|c|}
\hline & BMI z score & WC & WHtR \\
\hline \multicolumn{4}{|c|}{ SBP (mmHg) } \\
\hline$\beta$ & 0.446 & 0.047 & -0.122 \\
\hline$P$ & 0.001 & 0.665 & 0.400 \\
\hline \multicolumn{4}{|c|}{ DBP (mmHg) } \\
\hline$\beta$ & 0.049 & 0.339 & 0.169 \\
\hline$P$ & 0.654 & $<0.001$ & 0.239 \\
\hline \multicolumn{4}{|c|}{$\mathrm{FPG}(\mathrm{mmol} / \mathrm{l})$} \\
\hline$\beta$ & 0.022 & 0.014 & 0.048 \\
\hline$P$ & 0.809 & 0.051 & 0.462 \\
\hline \multicolumn{4}{|c|}{$\mathrm{TC}(\mathrm{mg} / \mathrm{dl})$} \\
\hline$\beta$ & -0.117 & -0.003 & 0.717 \\
\hline$P$ & 0.434 & 0.005 & 0.006 \\
\hline \multicolumn{4}{|c|}{$\mathrm{TG}(\mathrm{mg} / \mathrm{dl})$} \\
\hline$\beta$ & 0.025 & 0.041 & 0.122 \\
\hline$P$ & 0.818 & 0.703 & 0.259 \\
\hline \multicolumn{4}{|c|}{ LDL-C (mg/dl) } \\
\hline$\beta$ & 0.011 & -0.041 & 0.096 \\
\hline$P$ & 0.918 & 0.703 & 0.374 \\
\hline \multicolumn{4}{|c|}{ HDL-C (mg/dl) } \\
\hline$\beta$ & 0.119 & -0.141 & 0.208 \\
\hline$P$ & 0.311 & 0.047 & 0.181 \\
\hline \multicolumn{4}{|c|}{ HOMA-IR } \\
\hline$\beta$ & 0.026 & 0.243 & 2.516 \\
\hline$P$ & 0.854 & 0.102 & $<0.001$ \\
\hline \multicolumn{4}{|c|}{ CRP (mg/dl) } \\
\hline$\beta$ & 0.130 & 0.147 & 2.677 \\
\hline$P$ & 0.367 & 0.324 & 0.001 \\
\hline
\end{tabular}

$\beta$ is the coefficient change. $\mathrm{SBP}=$ Systolic blood pressure, $\mathrm{DBP}=$ Diastolic blood pressure, $\mathrm{FPG}=$ Fasting plasma glucose, HOMA-IR = Homeostasis model assessment of insulin resistance, TC $=$ Total cholesterol, LDL-C = Low density lipoprotein-cholesterol, $\mathrm{TG}=$ Triglyceride, HDL-C $=$ High-density lipoprotein-cholesterol, CRP $=$ C-reactive protein.

risk factors. Systolic blood pressure and insulin resistance were significantly associated with grade of obesity. Blood pressure, insulin resistance and CRP increased while HDL decreased with increasing severity of obesity. Moreover, among measures of obesity, BMI z score was a significant predictor of systolic blood pressure while waist circumference was an independent predictor of diastolic blood pressure and HDL. Waist height ratio best predicted insulin resistance, CRP and total cholesterol in overweight/obese children.

Our findings suggest that metabolic syndrome is far more common (69.3\%) among overweight and obese children and adolescents than previously reported. The prevalence of the metabolic syndrome was $6.8 \%$ among overweight and $28.7 \%$ among obese adolescents in a study conducted from 1988 to 1994 in USA [27]. The rate was $38.7 \%$ in moderately obese and in $49.7 \%$ of severely obese North American children in 1999 [9]. Various studies among obese children and adolescents show that the prevalence of metabolic syndrome varies from $28.7 \%$ to 50\% [27] [28]. However, meta-analysis of Tailor et al. shows that rate of me- 
tabolic syndrome can be up to $60 \%$ in the overweight and obese which is not markedly different from the finding of our study [29]. Metabolic syndrome was identified in $36.6 \%$ of obese children and adolescent ( 6 - 18 y) attending paediatric endocrine OPD of BIRDEM, Dhaka which is also much lower than our study population [30]. There are several definitions for metabolic syndrome in children. Therefore, the criteria used to define metabolic syndrome may influence its prevalence in this group. In addition, cut-off points used to define other cardiometabolic risk factors, ethnicity and eating behavior may also be contributing factors for the different prevalence of metabolic syndrome [9] [27] [28]. In our study, the high rate of metabolic syndrome may be due to the fact that all of the participants had central obesity, were mostly from urban area and were of high and middle socioeconomic condition. We found a high prevalence of dyslipidemia $(88.6 \%)$ compared to other studies that reported rates ranging from $42.9 \%$ to $69.9 \%$ [31] [32] [33]. Variations in reported prevalence rates of dyslipidaemia may be due to dietary habits in different cultures, different ethnicity, different inclusion criteria, BMI variation and differences in dyslipidaemia definition.

Among all the cardiometabolic risk factors, only systolic blood pressure and insulin resistance were significantly associated with grade of obesity (classified using BMI). In other words, children with grade 3 obesity had higher blood pressure and abnormal glucose metabolism. This indicates that grade 3 obesity represents a higher risk group among obese children. Since all subjects had central obesity, participants could not be compared on the basis of waist circumference or waist height ratio.

Systolic blood pressure correlated with different measures of obesity (mostly WC). However, BMI z score was the main predictor of systolic blood pressure in overweight/obese children. Similar to this study, a study done in Australian children showed that BMI was the best predictor for systolic blood pressure, where blood pressure increased by $1.05 \mathrm{mmHg}$ for every one unit increase of BMI. [34] Furthermore, in a multivariate analysis done by Moser et al. on 1441, 10 - 16 year old Brazilian students only BMI was a predictor of high blood pressure (Odds ratio $=2.9$ ), whereas WC and WHtR were not associated with risk of high blood pressure [35]. In contrast to our finding, WHtR was better than BMI for predicting hypertension [36]. On the other hand, a cross sectional study done in 1044 overweight and obese Italian children showed both WC and WHtR predicted high blood pressure in obese boys and girls [37]. WC was a significant predictor of both systolic and diastolic blood pressure in pre pubertal Chinese boys and girls [38].

HDL-C decreased with increasing WC, which was an independent predictor. In accordance with our finding, a meta-analysis stated that WHtR, closely followed by WC was an indicator of dyslipidaemia [37].

This study showed that insulin resistance and CRP correlated most with WHtR. In addition, WHtR independently predicted development of insulin re- 
sistance and CRP. In accordance with our study, Kondaki et al. showed greatest correlation of insulin resistance with WHtR [39]. On the other hand, a study from India observed strongest correlation of insulin resistance with WC [40]. Other studies also show significant increment of HOMA-IR with BMI, WC and WHtR mimicking our experience [41]. Our finding is in accordance with other studies which demonstrated that WHtR was a better anthropometric measure of obesity than WC and BMI for predicting cardiometabolic risk factors in adults and children [37] [42]. A study in pediatric population however stated that WC rather than BMI was the main predictor of cardiovascular disease [43].

Waist circumference and waist height ratio are measures of central obesity and correlate with intra-abdominal visceral fat, which is implicated in the pathogenesis of cardiometabolic disease [44]. BMI does not give us information about the distribution of fat and cannot differentiate between muscle and fat mass [45] [46]. Therefore, it is understandable and expected that insulin resistance, inflammatory markers and lipids correlate most with WHtR. However, SBP was related with BMI z score, a marker of generalized obesity. Therefore, according to this study, no single anthropometric measure can predict cardiometabolic risk in children.

A limitation of the study is that we could not measure insulin resistance with euglycaemic clamp. Future research on the cellular mechanism linking obesity and cardiovasvular risk can be undertaken to better understand the pathophysiology of these disorders.

There was a high rate of cardiometabolic risk factors in Bangladeshi overweight and obese children. Children with grade 3 obesity had worse cardiometabolic risk. Worsening of systolic blood pressure, insulin resistance, CRP and HDL were associated with increasing obesity. Although measures of central obesity best predicted insulin resistance, inflammation and lipids, no single anthropometric measure can predict cardiometabolic risk in children.

\section{Acknowledgements}

We would like to thank BSMMU for funding the research and the department of Microbiology, BSMMU for their technical support.

\section{Conflicts of Interest}

The authors declare no conflicts of interest regarding the publication of this paper.

\section{References}

[1] Ogden, C., Carroll, L., Kit, B. and Flegal, A. (2014) Prevalence of Childhood and Adult Obesity in the United States, 2011-2012. Journal of American Medicine Association, 311, 806-814. https://doi.org/10.1001/jama.2014.732

[2] Steinberger, J., Daniels, S.R. and Eckel, R.H. (2009) Progress and Challenges in Metabolic Syndrome in Children and Adolescents: A Scientific Statement from the American Heart Association Atherosclerosis, Hypertension, and Obesity in the 
Young Committee of the Council on Cardiovascular Disease in the Young; Council on Cardiovascular Nursing; and Council on Nutrition, Physical Activity, and Metabolism. Circulation, 119, 628-647. https://doi.org/10.1161/CIRCULATIONAHA.108.191394

[3] Reilly, J.J. (2005) Descriptive Epidemiology and Health Consequences of Childhood Obesity. Best Practice \& Research: Clinical Endocrinology, 19, 327-341.

https://doi.org/10.1016/j.beem.2005.04.002

[4] Goodman, E., Dolan, L.M., Morrison, J.A. and Daniels, S.R. (2005) Factor Analysis of Clustered Cardiovascular Risks in Adolescence: Obesity Is the Predominant Correlate of Risk Among Youth. Circulation, 111, 1970-1977.

https://doi.org/10.1161/01.CIR.0000161957.34198.2B

[5] Caprio, S. (2002) Insulin Resistance in Childhood Obesity. Journal of Pediatric Endocrinology and Metabolism, 15, 487-492.

[6] Burke, V., Beilin, L.J., Simmer, K., Oddy, W.H. and Blake, K.V. (2005) Predictors of Body Mass Index and Associations with Cardiovascular Risk Factors in Australian Children: A Prospective Cohort Study. International Journal of Obesity, 29, 15-23. https://doi.org/10.1038/sj.ijo.0802750

[7] Ahrens, W., Pigeot, I. and Pohlabelnetal, H. (2014) Prevalence of Overweight and Obesity in European Children below the Age of 10. International Journal of Obesity, 38, 99-107. https://doi.org/10.1038/ijo.2014.140

[8] Gungor, N. (2014) Overweight and Obesity in Children and Adolescents. Journal of Clinical Research in Pediatric Endocrinology, 6, 129-143.

https://doi.org/10.4274/jcrpe.1471

[9] Weiss, R., Dziura, J. and Burgert, T.S. (2004) Obesity and the Metabolic Syndrome in Children and Adolescents. The New England Journal of Medicine, 350, 2362-2374. https://doi.org/10.1056/NEJMoa031049

[10] Baker, J.L., Olsen, L.W. and Sorensen, T.I.A. (2007) Childhood Body-Mass Index and the Risk of Coronary Heart Disease in Adulthood. The New England Journal of Medicine, 357, 2329-2337. https://doi.org/10.1056/NEJMoa072515

[11] Gunnell, D.J., Frankel, S.J., Nanchahal, K., Peters, T.J. and Smith, G.D. (1998) Childhood Obesity and Adult Cardiovascular Mortality: A 57-y Follow-Up Study Based on the Boy D or R Cohort. The American Journal of Clinical Nutrition, 67, 1111-1118. https://doi.org/10.1093/ajcn/67.6.1111

[12] CDC Centers for Disease Control and Prevention, National Center for Health Statistics (2000). https://www.cdc.gov/growthcharts/clinical_charts.htm

[13] Skinner, A.C. and Skelton, J.A. (2014) Prevalence and Trends in Obesity and Severe Obesity among Children in the United States, 1999-2012. Journal of American Medical Association Paediatric, 168, 561-566. https://doi.org/10.1001/jamapediatrics.2014.21

[14] CDC Centers for Disease Control and Prevention, National Center for Health Statistics (2009). https://www.cdc.gov/growthcharts/zscore.htm

[15] El-Koofy, N.M., Anwar, G.M., El-Raziky, M.S., El-Hennawy, A.M., El-Mougy, F.M. and El-Karaksy, H.M. (2012) The Association of Metabolic Syndrome, Insulin Resistance and Non-Alcoholic Fatty Liver Disease in Overweight/Obese Children. Saudi Journal of Gastroenterology, 18, 44-49. https://doi.org/10.4103/1319-3767.91738

[16] Yan, W., Liu, F. and Li, X. (2013) Blood Pressure Percentiles by Age and Height for Non-Overweight Chinese Children and Adolescents: Analysis of the China Health and Nutrition Surveys 1991-2009. BMC Pediatrics, 13, 195. 
https://doi.org/10.1186/1471-2431-13-195

[17] Falkner, B. and Daniels, S.R. (2004) Summary of the Fourth Report on the Diagnosis, Evaluation, and Treatment of High Blood Pressure in Children and Adolescents. Hypertension, 44, 387-388. https://doi.org/10.1161/01.HYP.0000143545.54637.af

[18] Ridker, P.M., Cannon, C.P. and Morrow, D. (2005) C-Reactive Protein Levels and Outcomes after Statin Therapy. The New England Journal of Medicine, 352, 20-28. https://doi.org/10.1056/NEJMoa042378

[19] Ridker, P.M., Danielson, E. and Fonseca, F.A. (2008) Rosuvastatin to Prevent Vascular Events in Men and Women with Elevated C-Reactive Protein. The New England Journal of Medicine, 359, 2195-207. https://doi.org/10.1056/NEJMoa0807646

[20] Yin, J., Ming, L. and Lu, X. (2013) Insulin Resistance Determined by Homeostasis Model Assessment (HOMA) and Associations with Metabolic Syndrome among Chinese Children and Teenagers. Diabetology \& Metabolic Syndrome, 5, 71.

https://doi.org/10.1186/1758-5996-5-71

[21] Genuth, S., Alberti, K.G. and Bennett, P. (2003) Expert Committee on the Diagnosis and Classification of Diabetes Mellitus. Follow-Up Report on the Diagnosis of Diabetes Mellitus. Diabetes Care, 26, 3160-3167. https://doi.org/10.2337/diacare.26.11.3160

[22] Gröber-Grätz, D., Widhalm, K., De Zwaan, Reinehr, T., Bluher, S., Schwab, K.O., et al. (2013) Body Mass Index or Waist Circumference: Which Is the Better Predictor for Hypertension and Dyslipidemia in Overweight/Obese Children and Adolescents? Association of Cardiovascular Risk Related to Body Mass Index or Waist Circumference. Hormone Research in Paediatrics, 80, 170-178. https://doi.org/10.1159/000354224

[23] Sharma, A.K., Metzger, D.L., Daymont, C., Hadjiyannaki, S. and Celia, J. (2015) LMs Tables for Waist-Circumference and Waist-Height Ratio Z-Scores in Children Aged 5-19 y in NHANES III: Association with Cardiometabolic Risks. Pediatric Research, 78, 723-729. https://doi.org/10.1038/pr.2015.160

[24] Kuriyan, R., Thomas, T., Lokesh, D.P., Nishita, R., Mahendra, A., Joy, R., et al. (2011) Waist Circumference and Waist for Height Percentiles in Urban South Indian Children Aged 3-16 Years. Indian Pediatrics, 48, 765-771.

https://doi.org/10.1007/s13312-011-0126-6

[25] Matthews, D.R., Hosker, J.P., Rudenski, A.S., Naylor, B.A., Teacher, D.F. and Turner, R.C. (1985) Homeostasis Model Assessment: Insulin Resistance and B Cell Function from Fasting Plasma Glucose and Insulin Concentration in Man. Diabetologia, 28, 412-419. https://doi.org/10.1007/BF00280883

[26] Andrabi, S.M.S., Bhat, M.H., Andrabi, S.R.S., Kamili, M.M.A., Imran, A., Nisar, I. and Nisar, U. (2013) Prevalence of Metabolic Syndrome in 8-18 Years Old School Going Children of Srinagar City of Kashmir, India. Indian Journal of Endocrinology and Metabolism, 17, 95-100. https://doi.org/10.4103/2230-8210.107812

[27] Cook, S., Weitzman, M., Auinger, P., Nguyen, M. and Dietz, W.H. (2003) Prevalence of a Metabolic Syndrome Phenotype in Adolescents: Findings from the Third National Health and Nutrition Examination Survey, 1988-1994. Archives of Pediatrics and Adolescent Medicine, 157, 821-827. https://doi.org/10.1001/archpedi.157.8.821

[28] Cruz, M.L., Weigensberg, M.J., Huang, T.T., Ball, G., Shbi, G.Q. and Goran, M.I. (2004) The Metabolic Syndrome in Overweight Hispanic Youth and the Role of Insulin Sensitivity. The Journal of Clinical Endocrinology \& Metabolism, 89, 108-113. https://doi.org/10.1210/jc.2003-031188 
[29] Tailor, A.M., Peeters, P.H., Norat, T., Vineis, P. and Romaguera, D. (2010) An Update on the Prevalence of the Metabolic Syndrome in Children and Adolescents. International Journal of Pediatric Obesity, 5, 202-213. https://doi.org/10.3109/17477160903281079

[30] Mohsin, F., Baki, A., Nahar, J., Akhtar, S., Begum, T., Azad, K., et al. (2011) Prevalence of Metabolic Syndrome among Obese Children and Adolescents. BIRDEM Medical Journal, 1, 21-25. https://doi.org/10.3329/birdem.v1i1.12382

[31] Elmaoğulları, S., Tepe, D., Uçaktürk, S.A., Kara, F.K. and Demirel, F. (2015) Prevalence of Dyslipidemia and Associated Factors in Obese Children and Adolescen. Journal of Clinical Research in Pediatric Endocrinology, 7, 228-234. https://doi.org/10.4274/jcrpe.1867

[32] Cizmecioglu, F.M., Hatun, S. and Kalaca, S. (2008) Metabolic Syndrome in Obese Turkish Children and Adolescents: Comparison of Two Diagnostic Models. The Turkish Journal of Pediatrics, 50, 359-365.

[33] Hashemipour, M., Soghrati, M., MalekAhmadi, M. and Soghrati, M. (2011) Anthropometric Indices Associated with Dyslipidemia in Obese Children and Adolescents: A Retrospective Study in Isfahan. ARYA Atherosclerosis, 7, 31-39.

[34] Ke, L., Brock, K.E., Cant, R.V., Li, Y. and Morrell, S.L. (2009) The Relationship between Obesity and Blood Pressure Differs by Ethnicity in Sydney School Children. American Journal of Hypertension, 22, 52-58. https://doi.org/10.1038/ajh.2008.308

[35] Moser, D.C., Giuliano Ide, C., Titski, A.C., Gaya, A.R., Coelho-e-Silva, M.J. and Leite, N. (2013) Anthropometric Measures and Blood Pressure in School Children. The Journal of Pediatrics, 89, 243-249. https://doi.org/10.1016/j.jped.2012.11.006

[36] Ashwell, M., Gunn, P. and Gibson, S. (2011) Waist to Height Ratio Is a Better Screening Tool than Waist Circumference and BMI for Adult Cardiometabolic Risk Factors: Systematic Review and Meta-Analysis. Obesity Reviews, 13, 275-286. https://doi.org/10.1111/j.1467-789X.2011.00952.x

[37] Maffeis, C., Banzato, C., Brambilla, P., Cerutti, F., Corciulo, N., Cuccarolo, G., et al. (2010) Insulin Resistance Is a Risk Factor for High Blood Pressure Regardless of Body Size and Fat Distribution in Obese Children. Nutrition, Metabolism \& Cardiovascular Diseases, 20, 266-273. https://doi.org/10.1016/j.numecd.2009.04.005

[38] He, Q., Zhang, X., He, S., Gong, L., Sun, Y., Heshka, S., et al. (2007) Higher Insulin, Triglycerides, and Blood Pressure with Greater Trunk Fat in Tanner 1 Chinese. $\mathrm{Ob}$ esity (Silver Spring), 15, 1004-1011. https://doi.org/10.1038/oby.2007.599

[39] Kondaki, K., Grammatikaki, E., Pavón, D.J., Manios, Y., Gonzales-Gross, M., Sjöstrom, M., et al. (2011) Comparison of Several Anthropometric Indices with Insulin Resistance Proxy Measures among European Adolescents: The Helena Study. European Journal of Pediatrics, 170, 731-739.

https://doi.org/10.1007/s00431-010-1322-4

[40] Misra, A., Vikram, N.K. and Arya, S. (2004) High Prevalence of Insulin Resistance in Post Pubertal Asian Indian Children Is Associated with Adverse Truncal Body Fat Patterning, Abdominal Adiposity and Excess Body Fat. International Journal of Obesity and Related Metabolic Disorders, 28, 1217-1226. https://doi.org/10.1038/sj.ijo.0802704

[41] Singh, Y., Garg, M.K., Tandon, N. and Marwaha, R.K. (2013) A Study of Insulin Resistance by HOMA-IR and Its Cut-Off Value to Identify Metabolic Syndrome in Urban Indian Adolescents. Journal of Clinical Research in Pediatric Endocrinology, 5, 245-251.

[42] Maffeis, C., Banzato, C. and Talamini, G. (2008) Waist to Height Ratio, a Useful 
Index to Identify High Metabolic Risk in Overweight Children. The Journal of Pediatrics, 152, 207-213. https://doi.org/10.1016/j.jpeds.2007.09.021

[43] Savva, S.C., Tornaritis, M., Savva, M.E., Kourides, Y., Panagi, A., Silikiotou, N., et al. (2000) Waist Circumference and Waist-to-Height Ratio Are Better Predictors of Cardiovascular Disease Risk Factors in Children than Body Mass Index. International Journal of Obesity and Related Metabolic Disorders, 24, 1453-1458.

https://doi.org/10.1038/sj.ijo.0801401

[44] Després, J.P. (2006) Is Visceral Obesity the Cause of the Metabolic Syndrome? Annals of Medicine, 38, 52-63. https://doi.org/10.1080/07853890500383895

[45] Neovius, M. and Rasmussen, F. (2008) Evaluation of BMI-Based Classification of Adolescent Overweight and Obesity: Choice of Percentage Body Fat Cutoffs Exerts a Large Influence. The COMPASS Study. European Journal of Clinical Nutrition, 62, 1201-1207. https://doi.org/10.1038/sj.ejcn.1602846

[46] Hall, D.M. and Cole, T.J. (2006) What Use Is the BMI? Archives of Disease in Childhood, 91, 283-286. https://doi.org/10.1136/adc.2005.077339 